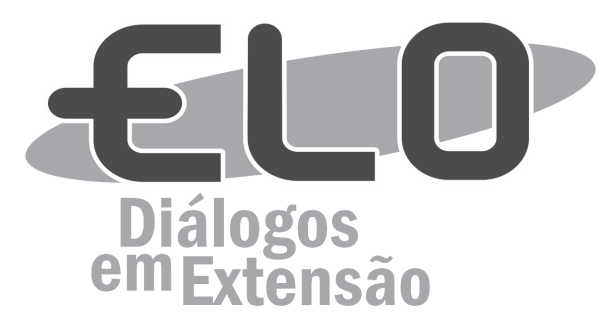

\title{
Festival de Inverno da Universidade Federal do Paraná (UFPR): quando o tempo do lazer é o tempo de fazer política pública para a cultura
}

Ronaldo de Oliveira Corrêa ${ }^{1}$; Romilda Aparecida da Silva ${ }^{2}$

\begin{abstract}
Resumo: O objeto desse texto e o Festival de Inverno da UFPR em Antonina-PR. Esse festival é uma politica cultural executada pela Universidade Federal do Paraná com o objetivo articular as práticas de pesquisa, ensino e extensão universitária com os processos coletivos de participação cidadã nas políticas públicas. Essa política cultural tem como metodologia a ação em três eixos: as oficinas, os espetáculos e as atividades de formação. Os três eixos têm por função constituir diferentes espaços de aprendizagem, reflexão crítica, produção e apreciação dos bens e conteúdos culturais. Pela sua perenidade - 26 edições sem interrupção - como atividade de estímulo e apoio a diferentes práticas, orientações estéticas e culturais, e por tomar como território físico a cidade de Antonina-PR, o festival é um patrimônio do litoral do Panará. Tem-se como resultado o estímulo das práticas e manifestações da cultura popular e multicultural, construindo um território simbólico das trocas estéticas que permitem discutir as trocas politicas. Dessa forma, o Festival estabelece como conclusões, o princípio ético, de estímulo e garantia da socialização, do encontro multicultural, geracional e de gênero, na medida em que esses processos de compartilhamento de espaços, temas e práticas permitam a democratização da cultura e da educação, a inclusão social e a valorização dos direitos humanos.
\end{abstract}

Palavras-chave: Políticas Culturais. Diversidade. Cidadania Cultural. Festival de Cultura.

Área Temática: Cultura, Direitos Humanos, Educação.

\section{Winter Festival of UFPR: when leisure time is time to make public policies for culture}

Summary: The Winter Festival of UFPR in Antonina-PR is a cultural policy implemented by the Federal University of Parana with the intent of articulating practices of research, teaching and university extension with the collective processes of citizen participation in public policies. This university cultural policy acts in three axes: workshops, performances and formation activities. The role of these three axes is to form different spaces of learning, critical reflection, production and appreciation of cultural goods and contents. We understand the Festival as a cultural heritage of the region of the coast of Parana. This is due to its longevity - 26 years without interruption - as an activity of stimulus and support of different practices, cultural and aesthetic orientations, taking as physical territory the city of Antonina-PR. This city, with a tradition of practices and expressions of popular and multicultural culture, becomes a symbolic territory of the aesthetic changes that allow the discussion of policy changes. As its purpose, the Festival has as an ethical principle to encourage and ensure the socialization, multicultural, generational and gender encounter, to the extent that these space, theme and practice sharing processes allow the democratization of culture and education, social inclusion and appreciation of human rights.

Keywords: Politics for Culture. Diversity. Cultural Citizenship. Culture Festival.

${ }^{1}$ Pró-Reitoria de Extensão e Cultura da Universidade Federal do Paraná (UFPR). Endereço: Travessa Alfredo Bufren, 140 - $3^{\circ}$ andar - Bairro Centro - CEP 80.020 240. Curitiba-PR. Telefone: (41) 3310 2631. E-mail: rcorrea@ufpr.br

${ }^{2}$ Pró-Reitoria de Extensão e Cultura da Universidade Federal do Paraná (UFPR). E-mail: romilda@ufpr.br 


\section{Festival del Invierno de la UFPR: cuando le tiempo de ocio es tiempo de hacer politica pública para la cultura}

Resumen: EL objeto de ese artículo es el Festival del Invierno da la UFPR en Antonina-PR. Ese festival es una politica cultural de la Universidad Federal del Paraná que tiene como objetivo la articulación de las practicas universitarias con los procesos colectivos de participación ciudadana en las políticas públicas. Esa política pública tiene como metodología la acción en tres ejes: los talleres, las presentaciones artísticas y las actividades de formación. Esos ejes tienen por propósito construir diferentes espacios de aprendizaje, reflexión crítica, producción e apreciación de los bienes y contenidos culturales. Su perennidad - 26 ediciones sin interrupción - como actividad de estímulo y apoyo a diferentes producciones culturales, orientaciones estéticas y culturales, y por ocupar Antonina-PR, el festival es un patrimonio del Litoral. Tenemos como resultados el estímulo a las prácticas y manifestaciones de la cultura popular e multicultural, construyendo un territorio simbólico donde los cambios simbólicos estimula e reflejan los cambios políticos. Al modo de conclusión, el Festival establece el principio ético, a medida en que el compartir espacios, temas y prácticas permitan la democratización de la cultura y de la educación, la inclusión social y la valorización de los directos humanos.

Palabras clave: Política para la cultura. Diversidad. Ciudadanía Cultural. Festival de Cultura.

\section{Introdução}

Esse texto tem por objetivo apresentar o Festival de Inverno da UFPR em Antonina-PR como uma ação para a cultura, formulada e executada no âmbito universitário, com o propósito de garantir o direito a bens e conteúdos que consolidam um tipo de cidadania cultural. Essa ação criada em 1991 como uma atividade inaugural voltada para arte e a cultura popular, da recém-criada Pró-Reitoria de Extensão e Cultura da UFPR ${ }^{3}$, foi reestruturada em 2013 a partir da articulação entre o projeto do Festival de Inverno da UFPR e as diretrizes estabelecidas no Plano Nacional de Cultura (Lei n 12.345, de 9 de dezembro de 2010), do Plano Nacional de Educação (Lei No13.005/2014) e do Plano Nacional de Extensão Universitária (FORPROEX, 2001).

O Festival é uma política cultural executada pela Coordenadoria de Cultura, unidade vinculada à Pró-Reitoria de Extensão e Cultura (PROEC) da Universidade Federal do Paraná (UFPR), com o propósito de articular as práticas de pesquisa, ensino e extensão com os processos coletivos de participação cidadã nas políticas públicas. Caracteriza-se por ser um programa de extensão universitária com atividades ao longo do ano, por meio de projetos vinculados, e de um evento que acontece no decorrer de uma semana na cidade de Antonina, no litoral do Paraná ${ }^{4}$ Esse caráter de programa de extensão para a área temática da cultura permite a formulação de atividades diversas que incluem espetáculos de música e dança, teatro e performance, assim como atividades de formação e entretenimento ${ }^{5}$.

Essa política cultural universitária tem por base um projeto gerador que é discutido anualmente de forma horizontal com os grupos e coletivos de produção artística, a sociedade civil organizada, as escolas municipais e estaduais do território do litoral e a equipe de técnicos e técnicas da Coordenadoria de Cultura da UFPR ${ }^{6}$. Tal processo constitui diferentes espaços de aprendizagem, reflexão crítica, produção e apreciação dos bens e conteúdos cultuais, assim como um maior envolvimento desses coletivos e instituições no debate e efetiva realização do evento/programa.

A (re)construção do projeto gerador se dá a partir da adesão ao deslocamento do conceito de cultura e de cidadania presente no Plano Nacional de Cultura (PNC), Plano Nacional de Educação (PNE) e no Plano Nacional de Extensão Universitária (PNEU). Tal deslocamento se apoia no questionamento a respeito da relevância das instituições (como as Universidades Públicas), na formulação e execução de políticas para a cultura e na proposição de marco regulatório que garanta as dinâmicas socioeconômicas de produção cultural, seu acompanhamento e crítica, mesmo que em uma escala reduzida. Esse marco regulatório é instrumentalizado por princípios e diretrizes que dão base para uma política de Estado a favor da ideia de cidadania cultural e educação plena em uma sociedade intercultural como a brasileira.

O conceito de cultura é pensado a partir da perspectiva antropológica. Dessa forma, entende-se a cultura não somente como um conjunto de bens estéticos da cultura oficial - o que nos conduziria a uma perspectiva patrimonialista - e sim como as práticas cotidianas - ordinárias e rituais - e suas produções de corpos e artefatos, práticas e imaginações (CHAUÍ, 2008). Entender a cultura como uma articulação entre o simbólico, o social e o econômico, ajuda a atentar e criticar, no projeto gerador 
do Festival de Inverno, o romantismo com o qual os bens e conteúdos culturais são operados no âmbito da cultura oficial e das políticas públicas. Ajuda, ainda, na desconstrução do idealismo vinculado ao mercado simbólico do cultural, seja esse monetário ou baseado na distinção social que ordena o acesso e os interesses em conteúdos e bens, e sua produção, circulação e consumo/ uso $^{7}$.

Para a constituição do conceito de cidadania cultural toma-se como base a ideia de que os cidadãos - entendidos como sujeitos sociais e políticos - têm na cultura uma forma de acessar diretos fundamentais como a educação plena e a dignidade (FLORES, 2009). A cidadania cultural, pensada como um conceito articulador entre direitos e deveres do indivíduo em face de sua comunidade e de uma comunidade em face de outra (LEITÃO, 2014) impõe ao Estado um deslocamento no sentido de garantir as condições necessárias para a (re)produção de práticas coletivas e individuais éticas e estéticas de diversas configurações.

Com isso, entende-se que a cidadania cultural é uma estratégia conceitual e política para desconstruir os dispositivos de dominação e discriminação, exclusão e marginalização, sejam esses culturais ou políticos, econômicos ou sociais existentes na realidade cultural brasileira (RUBIO, 2014). Ademais, é uma possibilidade para a construção da participação de atores e coletivos sociais na vida política e cultural do país. Essa abertura do conceito de cidadania cultural nos permite refletir sobre "qual Cultura [sic] queremos produzir e vivenciar nos próximos dez anos" (MinC, 2012:08), ou ainda, formular políticas públicas que possam “(...) assegurar o total exercício dos direitos culturais dos brasileiros e das brasileiras de todas as situações econômicas, localizações, origens étnicas e faixas etárias" (MinC, 2012:08).

Ao encarar a cultura como uma construção social - por ser coletiva e compartilhada -, relacional e situada, explicitam-se as relações diretas dessa com a história e com a política. Pensar nesses termos possibilita, ainda, problematizar as questões contemporâneas que envolvem a cultura enquanto bem e conteúdo, prática e política; dito de outra forma, como um campo potencial para o exercício das vivências interculturais e a consolidação da ideia de diversidade cultural. O conceito de cultura articulado à ideia de cidadania cultural evidencia as práticas e estéticas situadas que explicitam as descontinuidades e transformações por que passa a produção cultural em um contexto determinado o brasileiro; explicitam as diferenças transformadas em desigualdades, que atravessam o tema da cultura, e as pretensões de hegemonia e controle de estéticas e práticas humanas.

Esse debate conceitual se operacionaliza na ação Festival de Inverno da UFPR a partir da socialização do conhecimento artístico com vistas à integração dos variados grupos produtores e fruidores que constituem a sociedade local às políticas culturais nacionais; do estímulo à vivência multicultural e interdisciplinar dos bens e conteúdos culturais, promovendo a inclusão de temas e práticas estéticas de grupos e coletivos culturais e comunitários; de servir como uma política cultural de democratização dos saberes científicos e artísticos com o propósito de valorizar tais saberes, gerar o debate sobre a diversidade cultural e fortalecer os processos de participação cidadã nas políticas públicas e de construir prática de acesso aos bens e conteúdos culturais, de respeito aos direitos humanos à educação plena e plural ${ }^{8}$.

Entende-se o Festival como patrimônio vivo da região do litoral paranaense ${ }^{9}$ pelo fato de sua perenidade - 25 edições sem interrupção - como atividade de estímulo e apoio a diferentes práticas, orientações estéticas e culturais e por tomar como território físico a cidade de Antonina-PR. Essa cidade, que possui longa tradição nas práticas e manifestações da cultura popular e multicultural, converte-se em território simbólico das trocas estéticas que permitem discutir as trocas políticas feitas nesse processo.

\section{Metodologia e Avaliação do Projeto}

O Festival de Inverno da UFPR em Antonina-PR é um programa de extensão universitária que realiza, entre outras atividades, um evento de uma semana com periodicidade anual no recesso escolar, há $25 \operatorname{anos}^{10}$. O evento Festival tem feito parte da vida da Cidade de Antonina, no que toca as possibilidades de integração social pelas práticas artísticas e culturais. De igual forma, faz parte da vida da comunidade universitária (professores, técnicos e estudantes) no que diz respeito à vivência extensionista e à integração da Universidade com a sociedade.

Ao entender a Universidade como um ator social que promove o desenvolvimento regional, por meio de projetos e ações para a educação e cidadania, os objetivos do projeto/evento são apresentados, de forma a executar as diretrizes e valores que lhe dão base, a saber: 
a) Criar um espaço aberto, gratuito e alternativo de práticas e reflexão crítica, de apreciação e produção artístico-cultural no território do litoral do Paraná, pensado a partir da articulação entre ensino, pesquisa e extensão universitária e das políticas públicas para a cultura;

b) Ofertar gratuitamente espetáculos de música instrumental/erudita e apresentações de conteúdos e bens que valorizem e promovam a diversidade cultural do país, em especial, do território do litoral do Paraná, com o propósito de intensificar a circulação de espetáculos e atividades artísticas fora da capital do estado;

c) Ofertar gratuitamente atividades de formação, como oficinas de música instrumental/erudita, artes cênicas, dança, artes visuais, literatura e artesanato, assim como de temas vinculados à cultura, gestão cultural, patrimônio cultural e demais áreas da cultura para a população local, em especial, artistas e produtores culturais que atuam na região do litoral do Paraná, com o propósito de aprimoramento profissional no setor cultural;

d) Ofertar gratuitamente cursos e treinamentos de aperfeiçoamento profissional, no que diz respeito a métodos e técnicas das áreas de formação artística e cultural para professoras e professores das redes públicas municipal e estadual, assim como para educadoras e educadores populares e agentes culturais do litoral do Paraná, com o propósito de elevar a qualidade do ensino nos temas relacionados à cultura, ao patrimônio cultural e à arte ${ }^{11}$.

De forma geral o evento Festival tem como eixos: as oficinas, os espetáculos e as atividades de formação. Por oficinas, entendem-se as atividades lúdicas e artísticas para crianças, jovens e adultos; por espetáculos, a programação com artistas locais e aqueles de reconhecimento nacional; por atividades de formação, o apoio e estímulo à formação e a capacitação das(os) professoras(es) das redes municipal, estadual e da educação especial, somado às associações de bairros, grupos/coletivos de artistas, agremiações carnavalescas e de folclore, entre outros.

Dessa Forma, o Festival de Inverno da UFPR, em Antonina-PR, é entendido e operacionalizado como um tempo/espaço de troca intensa e intercultural, onde as vivências políticas, éticas e estéticas são mediadas pelo encontro e a confraternização entre a sociedade e a comunidade acadêmica, com o propósito de construir a cultura como espaço de conhecimento e vivência dos direitos humanos e da educação plena e plural.

O Programa de Extensão Festival de Inverno da UFPR em Antonina, registrado sob o código 129/ 14, no Sistema Integrado de Gestão da Extensão Universitária (SIGEU-UFPR), tem como uma das ações o evento "Festival de Inverno da UFPR". Sua avaliação institucional se dá por meio da apreciação pelo Comitê Assessor de Extensão (CAEX) - formado por professores e professoras, discentes e técnicos administrativos da UFPR - dos relatórios anuais submetidos à plataforma SIGEU.

O relatório é constituído pela apresentação da proposta e seus objetivos, sua justificativa e metodologia, os recursos humanos da UFPR e de instituições parceiras, a descrição das atividades realizadas no ano, o detalhamento dos produtos e publicações, ações e objetivos alcançados. Esse relatório é documentado com imagens, arquivos e material que comprovam a realização das ações e informam as estratégias para sua execução e avaliação.

Tal documentação é, então, avaliada respeitando os princípios do Plano Nacional de Extensão Universitária (2001) que dispõe sobre a avaliação desses projetos e programas a partir de três níveis inter-relacionados: "1. O compromisso institucional para a estruturação e efetivação das atividades de extensão; 2. O impacto das atividades de extensão junto aos segmentos sociais que são alvos ou parceiros dessas atividades; 3 . Os processos, métodos e instrumentos de avaliação das atividades de extensão" (FORPROEX, 2001, p. 28).

Complementar a esse procedimento, a avaliação da equipe da Coordenadoria de Cultura explicita que, na dimensão simbólica, consegue-se socializar gratuitamente o conhecimento artístico com vistas à integração dos grupos produtores e fruidores que constituem a sociedade do litoral do Paraná às políticas culturais nacionais. Com isso, valoriza-se e divulga-se a produção cultural local de forma a fortalecer os laços de identidade, a autoestima desses artistas e coletivos daquele território. Por outro lado, são fortalecidas as instituições de ensino formais e informais aproximando as professoras e os professores dos bens e conteúdos culturais locais e regionais para a manutenção das expressões culturais do litoral do Paraná.

No âmbito da economia para a cultura, intensifica-se a formação e o aprimoramento profissional no setor cultural; amplia-se o acesso de uma determinada população aos bens e conteúdos culturais, bem como, proporciona-se o desenvolvimento local e, consequentemente, regional, por meio do 
reconhecimento e consolidação do litoral do Paraná como um território criativo. O Festival de Inverno da UFPR potencializa essa região como um destino turístico com vocação cultural associado à preservação do patrimônio histórico e desenvolvimento sustentável.

No que toca à dimensão cidadã, o Festival de Inverno da UFPR contribui para a consolidação das práticas democráticas de valorização da produção intercultural que tratam do tema da diversidade por meio da participação social na formulação, execução e fiscalização das ações para a cultura em âmbito local, regional e nacional. Isso se dá por meio da organização e da participação dos grupos locais junto aos técnicos da UFPR nas reuniões para a formulação da proposta do Festival e suas ações; exigência de melhoria da infraestrutura cultural do município de Antonina-PR; e a garantia e ampliação de acessibilidade às pessoas com deficiências e idosas nas atividades e ações.

Dessa forma, institucionalizar as ações para a cultura por meio dos dispositivos da extensão possibilita concebê-las como um processo orgânico e contínuo de articulação entre o ensino, a pesquisa e a extensão na mobilização de uma relação transformadora entre universidade e sociedade, atendendo assim, às orientações do Fórum de Pró-Reitores de Extensão - FORPROEX. Assim, busca-se orientar as ações para a cultura a partir de uma metodologia de acompanhamento e avaliação de atividades já estruturada no âmbito da UFPR.

\section{Resultados}

Como alguns dos resultados do "Festival de Inverno da UFPR", apresentamos os dados quantitativos e qualitativos. No ano de 2015, foram realizadas 25 apresentações musicais (nos gêneros erudito, instrumental e popular); 03 apresentações de dança (clássico e contemporâneo); 27 oficinas (abrangendo as diferentes categorias, como infantil, adulto, aprimoramento, arte-educação que foram executadas com ministrantes oriundos de diversas regiões do país); 03 vivências (vinculadas a projetos e programas de extensão e pesquisa da UFPR) e 12 atividades paralelas (entre exposições, passeios ciclísticos, mostra de cinema, lançamentos de livros, palestras, entre outros, promovidos pela UFPR e demais parceiros).

A descrição das atividades pode ser verificada no caderno de "Programação Geral" ou no site do evento $^{12}$. Contou-se, ainda, com um dia de atividades paralelas realizadas pelo Diretório Central dos Estudantes (DCE), de forma a proporcionar maior integração das instâncias de representação estudantil e o Festival de Inverno da UFPR.

Para promover a democratização dos conteúdos e vivências culturais no/pelo Festival de Inverno da UFPR, estabeleceu-se o diálogo com os coletivos que representam os diferentes setores da sociedade de Antonina. Isso, para realizar o planejamento e gestão do Festival de forma participativa e plural. Foram realizadas reuniões mensais, no período de fevereiro a julho, nas quais foram tratados o tema, a programação, a atmosfera gráfica, a infraestrutura e os projetos de extensão vinculados ao festival. As Associações de Bairro foram convidadas a se tornarem parceiras na descentralização das atividades e as escolas (urbanas e rurais) fizeram parte do Festival, não apenas no processo de descentralização física, mas também formulando e executando atividades que envolveram as metodologias discutidas no decorrer do processo de formação ${ }^{13}$.

As oficinas e demais atividades foram oferecidas sem custos para a população/participante das atividades (incluindo inscrição e material necessário para a realização da atividade). Os espetáculos foram realizados em espaços públicos e de forma gratuita, mesmo quando necessária a restrição de público em função da segurança ou acessibilidade.

Nessa edição, para efetivar a descentralização das atividades, foi realizada uma das apresentações na Igreja de São João Batista - no bairro do Batel. Tal apresentação contou com a mobilização daquela comunidade na organização e divulgação da atividade. Experimentou-se, assim, outro modelo de ocupação da cidade e de participação da população de diferentes territórios simbólicos e físicos. $\mathrm{O}$ Festival se transformou em arena irradiadora (simbólica e física) de cultura e cidadania. O que se pretendeu com esse modelo foi a abertura à fruição de populações antes isoladas ou não envolvidas com as atividades, em especial aquela localizada na periferia.

Como parte dos resultados, houve a coleta e entrega de alimentos para instituições como a Associação de Pais e Amigos dos Excepcionais (APAE) ${ }^{14}$

Além disso, contou-se com o apoio ao grupo de mulheres da Associação de Moradores do Bairro do Batel (AMBB), que por meio do projeto “Criar de Corte e Costura da AMBB”, desenvolveu e produziu 
as sacolas que contiveram os kits do Festival de inverno, como pode ser verificado na postagem do evento nas redes sociais, ou ainda na página da $\mathrm{AMBB}^{15}$. Esse processo foi resultado do envolvimento da Associação de Bairro nas reuniões, sendo esse protagonista dos encaminhamentos e decisões sobre as ações a serem desenvolvidas no Festival de inverno.

Atentar para as questões ambientais na realização de eventos como o Festival de Inverno da UFPR, significa explicitar as consequências não só ambientais, mas também aquelas socioculturais decorrentes da reunião de um número considerável de pessoas por um período de tempo curto, na Cidade de Antonina-PR. As medidas preventivas a impacto ambiental foram realizadas como contrapartida da Prefeitura Municipal de Antonina-PR, de acordo com o Termo de Cooperação Técnica firmado entre a Prefeitura Municipal de Antonina e a UFPR. Entre outras medidas, realizou-se a disponibilização de banheiros químicos, lixeiras e a manutenção dos serviços de limpeza pública e coleta de lixo.

Com relação às questões socioculturais que desdobram em medidas de impacto ambiental, em 2015 foram desenvolvidas atividades como a oficina de bioarquitetura que tratou das formas que o ambiente construído pode influenciar as formas de vida local, atentando para a relação de uso dos materiais e dos espaços. Junto à oficina, foi realizada uma mesa-redonda sobre o tema da bioarquitetura e do patrimônio cultural para discutir os usos do ambiente construído relacionado às políticas de patrimônio nacionais e regionais. Essa mesa-redonda contou com a participação do Superintendente do Instituto do Patrimônio Histórico e Artístico Nacional (IPHAN) no Paraná, o arquiteto José La Pastina Filho.

O estímulo ao turismo e, consequentemente, à projeção da cidade como um lugar para visitação e entretenimento foi outra estratégia para a reflexão a respeito das questões ambientais. Para isso, foram realizadas oficinas de roteiros turísticos em Antonina. Outra iniciativa foi uma vivência intitulada "Litoral Paranaense: uma experiência dos sentidos", desenvolvida por estudantes do curso de Turismo da UFPR.

A maior circulação de pessoas ajuda a dar visibilidade ao patrimônio paisagístico do território de Antonina-PR, movimenta o comércio e o setor de serviços de recepção e hospedagem. Para tanto, foram realizadas vivências que estimulassem as experiências com a cultura litorânea (elementos da paisagem, as comidas e produtos típicos, os hábitos e práticas locais), como o tema da educação ambiental por meio da oficina pintura com solos, que teve por tema as paisagens da cidade.

Foram desenvolvidas ações para que a acessibilidade às atividades pudesse ser realizada na medida do possível. Entre elas, criou-se o projeto de sinalização/orientação dos espaços, no qual as atividades foram realizadas. Tal projeto foi desdobrado em informações disponibilizadas no site do evento, como as formas de acesso à cidade e aos lugares de atividades. Junto a isso, a acessibilidade física foi uma preocupação no momento em que o Festival foi descentralizado e multi-sede. Para os espaços físicos onde as atividades aconteceram, contou-se com a estrutura já existente na cidade. A estratégia de descentralização pretendeu alcançar aqueles grupos e populações que não tinham acesso aos conteúdos e bens culturais. Tudo isso no intuito de incluir os diferentes segmentos da sociedade e democratizar de forma gratuita a produção cultural.

Entendeu-se que o projeto de acessibilidade urbana é um debate que deve envolver a população, o poder público e a equipe de organização. Entendeu-se, ainda, que uma cidade acessível deva fazer parte de um planejamento complexo recente. Todavia, pretendeu-se levar o debate para o âmbito da proposta do Festival, que passou a ser mais um eixo, no qual a reflexão, pesquisa e extensão universitária apoiaram a tomada de decisão para as políticas públicas realizadas. No que toca a possibilidade de qualquer público fruir o Festival, verificou-se algumas limitações, que foram problematizadas e compartilhadas com a sociedade civil organizada e o poder público de Antonina, com o propósito de estabelecer um levantamento desses pontos e estudo das estratégias para futuros encaminhamentos.

Como estratégia para promover a democratização dos conteúdos e vivências culturais promovidas no/pelo Festival de Inverno da UFPR, estabeleceu-se o diálogo com os coletivos que constituem/ representam os diferentes setores da sociedade de Antonina. A finalidade disso foi realizar o planejamento e gestão de forma participativa e plural, tendo como motivação a integração da comunidade no processo de reflexão sobre o Festival como bem cultural e, possivelmente, herança cultural do litoral. 
No âmbito da difusão acadêmica o programa "Festival de Inverno da UFPR" e seus projetos vinculados foram apresentados e debatidos na Semana Integrada de Ensino, Pesquisa e Extensão Universitária (SIEPE) da UFPR ${ }^{16}$ que aconteceu nos dias 5, 6 e 7 de outubro e também no $2^{\circ}$ Congresso de Extensão da Associação de Universidades do Grupo de Montevideo (AUGM), que ocorreu entre os dias 9 e 12 de outubro na Universidade Estadual de Campinas - UNICAMP17.

Ainda no âmbito da divulgação para o público em geral, o Festival de Inverno foi tema do primeiro número do TOM_UFPR - Caderno de Ensaios $^{18}$. A publicação foi uma ação de comunicação para a cultura realizada pela UFPR, que atende às diretrizes definidas pelo Ministério da Cultura (MinC) no Plano Nacional de Cultura (Lei $N^{\circ} 12.343 / 2010$ ) para a disponibilização de informações em meios consolidados como o rádio e a TV, as revistas e os jornais, bem como aqueles ainda em consolidação, como as plataformas compartilhadas e as redes sociais em ambiente da internet. O primeiro número dessa publicação teve divulgação no âmbito da comunidade acadêmica por meio da UFPRTV e pelo programa UFPR Notícias de 24/08/2015

Acredita-se que as atividades realizadas repercutiram no cotidiano das comunidades de Antonina e da UFPR (servidores, professores e estudantes) de forma a instigar a integração e ação em atividades culturais e artísticas, promovendo o acesso aos bens e conteúdos culturais e estimulando as práticas interculturais de educação plena e direitos humanos.

\section{Conclusão}

Ao longo das suas 25 edições, gerações de crianças, jovens e adultos do litoral do Paraná são sensibilizadas e vivenciam práticas, conteúdos e bens culturais das mais diferentes orientações estéticas, a saber: música clássica e popular, artes visuais e performances teatrais, dança das diferentes tradições - desde a clássica àquelas populares do litoral. Além disso, conta-se com a formação e aperfeiçoamento, no que se pode chamar de inovação social/economia criativa ${ }^{20}$. Dito de outra forma, o Festival serve de veículo para o debate e formação das habilidades e conhecimentos que dão suporte para a autonomia dos diferentes coletivos que constituem as sociedades litorâneas, com o propósito de transformação social desses territórios. Isso acontece por meio da construção participativa e horizontal dos temas e programação do Festival de Inverno da UFPR. Também inclui, em 2015, a prática de reuniões abertas e consultas públicas aos grupos organizados da sociedade civil (Associações de Bairro, Grupos/Coletivos de Artistas, Escolas Municipais e Estaduais, Administração Pública) sobre os temas de interesse e as necessidades locais.

Salientamos, ainda, o amadurecimento do debate interno a respeito da relevância social, econômica e, principalmente, política dos temas abordados nesse programa de extensão universitária, tais como diversidade e direitos culturais. Esse debate desdobrou-se na formulação e aprovação de outros projetos, por exemplo, Diversidade e Direitos Culturais, uma parceria entre a Coordenadoria de Cultura e a Coordenadoria de Políticas Sociais da UFPR, que pretende constituir uma rede de parceiros e um fórum de discussões sobre cidadania e cultura.

Portanto, o Festival viabiliza a integração de diferentes atividades de pesquisa e extensão desenvolvidas na UFPR ao promover um espaço, no qual essas ações são exercitadas coletivamente. $O$ desafio à comunidade acadêmica se localiza no compromisso ético de difusão dos conhecimentos produzidos no âmbito da Instituição. Somado a isso, a formação de práticas de cidadania da comunidade acadêmica, rompendo com as ideias preconcebidas de distanciamento estrutural da universidade pública com os coletivos que constituem a sociedade local e nacional.

\section{Agradecimentos}

Agradecemos à Pró-Reitoria de Extensão e Cultura da UFPR por autorizar o uso dos dados e dar acesso aos documentos que dão base para esse texto.

\section{Fontes de Financiamento}

As atividades desenvolvidas no Programa de Extensão Festival de Inverno da UFPR em AntoninaPR foram realizadas com recurso financeiros institucionais, por meio de bolsas de extensão e bolsas Cem Anos, além de voluntariado acadêmico. Utilizou-se, ainda, recurso do Fundo Desenvolvimento Acadêmico (FDA), oriundo do edital interno de 2016. O FDA é um instrumento interno para financiamento de projetos e programas de interesse institucional no âmbito da UFPR. 


\section{Referências}

CHAUÍ, Marilena. Cultura e Democracia. In: Crítica y emancipación: Revista Latinoamericana de Ciencias Sociales. Año 1, nº 1 (jun. 2008- ). Buenos Aires: CLACSO, 2008. - ISSN 1999-8104.

FARACO, Carlos Alberto; KERSTEN, Márcia Schoulz de Andrade; FONTOURA, Márcia Simões da. "Festival de Inverno da UFPR em Antonina". In: TOM, caderno de ensaios. Curitiba: Coordenadoria de Cultura - PROEC-UFPR. Jan/ago 2015. Disponível em: <http://issuu.com/tom_ufpr/docs/tom1>. Acesso em: 15 de dez. de 2015.

FLORES, Joaquín Herrera. A (re)invenção dos direitos humanos. Florianópolis: Fundação Boiteux, 2009.

FORPROEXT. Sistema de Dados e Informações: Base Operacional de acordo com o Plano Nacional de Extensão Universitária. Fórum de Pró-Reitores de Extensão das Universidades Públicas Brasileiras. Rio de Janeiro: NAPE, UERJ, 2001. (Coleção Extensão Universitária; v.2).

LA PASTINA FILHO, José; ONO, Lia Mity; NARDI, Letícia “Festival de Inverno - Patrimônio vivo de Antonina". In: TOM, caderno de ensaios. Curitiba: Coordenadoria de Cultura - PROEC-UFPR. Jan/ ago 2015. Disponível em: <http://issuu.com/tom_ufpr/docs/tom1>. Acesso em: 15 de dez. de 2015.

LEITÃO, Claudia Souza; GUILHERME, Luciana Lima. Cultura em Movimento - Memórias e Reflexões sobre Políticas Públicas e Práticas de Gestão. Fortaleza-CE: Ed. Armazém da Cultura, 2014.

MINISTÉRIO DA CULTURA. As Metas do Plano Nacional de Cultura. São Paulo: Instituto Via Pública; Brasília: MinC, 2012.

MIRANDA, Gabriel. "O início dos 25 anos de uma Semana Mágica". In: TOM, caderno de ensaios. Curitiba: Coordenadoria de Cultura - PROEC-UFPR. Jan/ago 2015. Disponível em: <http:/ / issuu.com/ tom_ufpr/docs/tom1>. Acesso em: 15 de dez. de 2015.

RUBIO, David Sánchez. Encantos e desencantos dos direitos humanos: de emancipações, libertações e dominações. Porto Alegre: Livraria do Advogado editora, 2014.

Recebido para publicação em 4/3/2016 e aprovado em 8/8/2016.

\footnotetext{
${ }^{3}$ A constituição de uma Pró-Reitoria de Extensão e Cultura no período é encarada como uma forma de resistência à instalação da ideologia do "Estado Mínimo" que ocorreu a partir da década de 1990: intensificação da instalação do neoliberalismo no país, desarticulação dos equipamentos do Estado nas áreas de saúde, educação e previdência, desestruturação da ideia de cidadania em favor da articulação entre cidadania e consumo. Para um panorama das motivações que resultaram na criação do Festival de Inverno como uma política institucional com caráter de resistência universitária à política pública nacional do período dos anos 1990, ver os artigos "O início dos 25 anos de uma Semana Mágica" de Gabriel Miranda e "Festival de Inverno da UFPR em Antonina" de autoria de Carlos Alberto Faraco, Márcia Schoulz de Andrade Kersten e Márcia Simões da Fontoura, no periódico digital TOM, cadernos de ensaios de agosto de 2015 < http:/ / issuu.com/tom_ufpr/docs/tom1>. Acesso em: 15 de dez. de 2015.

${ }^{4}$ Os projetos vinculados tratam dos temas da memória, do registro e da formação, são eles: "Memória Gráfica do Festival de Inverno da UFPR em Antonina"; "Formação Docente Integrada ao Festival de Inverno da UFPR", e "Estratégias de Comunicação para o Festival de Inverno da UFPR em Antonina". O registro das atividades do evento/programa de extensão universitária Festival de Inverno da UFPR está disponível em: <www.proec.ufpr.br/festival2015>, <https:// www.facebook.com/FestivalDeInvernoDaUfpr/?fref=ts $>$ e em < https:/ / www.facebook.com/UFPRArteECultura/?fref=ts>. Acesso em: 15 de dez. de 2015.

${ }^{5}$ No documento do Plano Nacional de Extensão Universitária, a área temática da cultura é assim caracterizada: "Desenvolvimento de Cultura; cultura, memória e patrimônio; cultura e memória social; cultura e sociedade; folclore, artesanato e tradições culturais; produção cultural e artística na área de artes plásticas e artes gráficas; produção cultural e artística na área de fotografia, cinema e vídeo; produção cultural e artística na área de música e dança; produção teatral e circense; rádio universitária; capacitação de gestores de políticas públicas do setor cultural; cooperação interinstitucional e cooperação internacional na área" (Plano Nacional de Extensão Universitária, 2001).

${ }^{6} \mathrm{O}$ território do litoral do Paraná é assim definido em consonância com a caracterização de território criativo do Plano Nacional de Cultura, a saber, "(...) são bairros, cidades ou regiões que apresentam potenciais culturais criativos capazes de promover o desenvolvimento integral e sustentável, aliando preservação e promoção de seus valores culturais e ambientais" (PNC, 2012:40). O território do Litoral do Paraná abrange os municípios de Paranaguá, Pontal do Paraná, Guaraqueçaba, Matinhos, Guaratuba, Antonina e Morretes. A caracterização do território se deu pelo fato da UFPR estar presente com unidades avançadas nos municípios de Matinhos e Pontal do Paraná e com a presença do Museu de Arqueologia e Etnologia da UFPR em Paranaguá, além de atividades de extensão e de pesquisa no município de Antonina. A UFPR atua como agente de desenvolvimento local e regional, ao ser protagonista nos debates sobre educação e cultura, saúde e políticas

públicas, entre outros temas.
${ }^{7} \mathrm{O}$ entendimento do conceito de cultura está em consonância com a articulação entre as dimensões simbólica, cidadã e econômica apresentada do documento "As metas do Plano Nacional de Cultura" publicado pelo Ministério da Cultura em 2012. Nesse documento, as dimensões apresentadas são tomadas como princípios que conduzem o diálogo sobre os temas da diversidade cultural, do circuito de criação, circulação, consumo dos bens e conteúdos culturais, da educação e gestão pública, da participação social na formulação, execução e fiscalização das políticas públicas, assim como dos temas do desenvolvimento econômico e sustentável - inclusive do fomento e do financiamento da/ para a cultura.

${ }^{8}$ Essas ações têm por objetivo alcançar aos grupos em situação de vulnerabilidade social, assim caracterizados a partir do Plano Nacional de Direitos Humanos PNDH-3 (Decreto No 7.037/2009, atualizado pelo Decreto No 7.177/2010) e a Convenção sobre a Proteção da Diversidade das Expressões Culturais, adotada pela Conferência Geral da Organização das Nações Unidas para a Educação, a Ciência e a Cultura - UNESCO em 2005, e promulgada pelo Decreto N $6.177 / 2007$ da Casa Civil da Presidência da República.
} 
${ }^{9}$ Com relação a esse caráter de patrimônio cultural, ver o texto "Festival de Inverno - Patrimônio vivo de Antonina", de autoria de José La Pastina Filho, Lia Mity Ono e Letícia Nardi do IPHAN, Superintendência do Paraná, publicado no TOM, caderno de ensaios de agosto de 2015.

${ }^{10}$ Desde 2013 o Festival de Inverno da UFPR foi registrado como programa de extensão universitária no Sistema Integrado de Gestão da Extensão Universitária (SIGEU-UFPR). Esse registro foi resultado de um processo de avaliação e reestruturação do Festival de Inverno, que gerou o alinhamento do evento com as diretrizes e valores do Plano Nacional de Extensão Universitária (FORPROEX, 2001). Como desdobramento foi desenvolvido ao longo dos anos de 2014 e 2015 três projetos vinculados ao evento/programa, já citados em nota, anteriormente.

${ }^{11}$ Projeto do Evento/Programa Festival de Inverno da UFPR - versão 2015.

${ }^{12}$ Disponível em: <http://www.proec.ufpr.br/festival2015>. Acesso em: 16 de dez. de 2015.

${ }^{13}$ Disponível em: < http:/ / www.ufpr.br/portalufpr/blog/noticias/acoes-do-festival-de-inverno-ja-iniciaram-em-antonina/>. Acesso em: 14 de dez. de 2015.

${ }^{14}$ Disponível em: <https:/ / ufprtv.wordpress.com/2015/07/20/ufpr-noticias-200715/>. Acesso em: 16 de dez. de 2015.

${ }^{15}$ Disponível em: <https:/ / www.facebook.com/FestivalDeInvernoDaUfpr?fref=ts>. Acesso em: 16 de dez. de 2015. Ver também em: <https://www.facebook.com/ media/set/?set=a.733414016785046.1073741904.302191956573923\&type=3>. Acesso em: 17 de dez. de 2015.

${ }^{16}$ Disponível em: <http://www.siepe.ufpr.br/>. Acesso em: 17 de dez. de 2015.

${ }^{17}$ Disponível em: <http:/ / www.preac.unicamp.br/augm/dadosaugm e https://www.facebook.com/PREAC-Pr\%C3\%B3-Reitoria-de-Extens\%C3\%A3o-e-AssuntosComunit\%C3\%A1rios-Unicamp-1507689112821339/timeline/?ref=hl>. Acesso em: 17 de dez. de 2015.

${ }^{18}$ Disponível em:<http://issuu.com/tom_ufpr/docs/tom1>. Acesso em: 17 de dez. de 2015.

${ }^{19}$ Disponível em: < https://ufprtv.wordpress.com/2015/08/24/ufpr-noticias-240815/>. Acesso em: 5 de jan. de 2016.

${ }^{20}$ Para o PNC, em seu documento de operacionalização, "As Metas..." o entendimento de economia criativa se dá da seguinte forma: "(...) é um setor estratégico e dinâmico, tanto do ponto de vista econômico como social: suas atividades geram trabalho, emprego, renda e inclusão social. A Economia Criativa é composta das atividades econômicas ligadas aos segmentos definidos pela Unesco: patrimônio natural e cultural, espetáculos e celebrações, artes visuais e artesanato, livros e periódicos, audiovisual e mídias interativas e design e serviços criativos" (MinC, 2012: 36). 